\title{
Compressive strength of calcium phosphate cements prepared using different initial setting temperatures
}

\author{
Takenori SAWAMURA, ${ }^{*, *, \dagger}$ Yoichiro MIZUTANI, ${ }^{*}$ Masahiko OKUYAMA, ${ }^{*}$ \\ Akiko OBATA** and Toshihiro KASUGA** $^{* *}$ \\ ${ }^{*}$ R \& D Center, NGK Spark Plug Co. Ltd., 2808 Iwasaki, Komaki, Aichi 485-8510, Japan \\ ***Nagoya Institute of Technology, Gokiso-cho, Showa-ku, Nagoya 4666-8555, Japan
}

\begin{abstract}
The effect of initial setting temperature on the compressive strength of calcium phosphate cements prepared using $\mathrm{Ca}_{4}\left(\mathrm{PO}_{4}\right)_{2} \mathrm{O}$ and $\mathrm{CaHPO}_{4}$ was examined. The strength of the initial setting bodies increased with increasing temperatures: the strength of the body heated at $100^{\circ} \mathrm{C}$ was $\sim 14 \mathrm{MPa}$, which was $\sim 7$ times higher than that heated at $37^{\circ} \mathrm{C}$. When the setting bodies were soaked in simulated body fluid at $37^{\circ} \mathrm{C}$ for $24 \mathrm{~h}$, they showed enhanced strength properties owing to the interlocking structure originating from hydroxyapatite formation. The extent of this effect increased with decreasing setting temperatures: the strength of the body heated at $37^{\circ} \mathrm{C}$ was $\sim 50 \mathrm{MPa}$, which was $\sim 3$ times higher than that heated at $100^{\circ} \mathrm{C}$. This was due to the rapid formation of hydroxyapatite following initial setting of the bodies treated at higher temperatures and the delayed hydration reaction following soaking in simulated body fluid.
\end{abstract}

(c)2015 The Ceramic Society of Japan. All rights reserved.

Key-words : Calcium phosphate cement, Initial setting temperature, Compressive strength, Hydroxyapatite, Hydration reaction

[Received July 30, 2014; Accepted October 25, 2014]

\section{Introduction}

Various calcium phosphate cements (CPCs) have been studied for application as bone substitutes. ${ }^{1), 2}$ Bone reconstruction using CPC paste, which has been shaped nearly into bone defect dimensions prior to implantation to body, is known as one of useful treatments in plastic surgery. ${ }^{3), 4)}$ In general, the surgical sites need to be sutured immediately after implantation of the $\mathrm{CPC}$ pastes to prevent any infection. During such intervention, inflammation around soft tissues owing to leakage of non-reacted raw CPC powders from the defect site can be observed. ${ }^{5)}$ Additionally, there is a serious concern about the fracture of CPC with insufficient mechanical strength when CPC setting is not enough. $\mathrm{CPC}$ is required to set in the desired time following formation of the CPC paste and maintain its shape during such operation.

It has been reported that additives, such as organic acids, in the CPC pastes can accelerate hydration reactions and reduce the setting time. ${ }^{6)}$ Shorter setting times can potentially lead to an unsuccessful operation, owing to rapid transformation processes. Additionally, treatment at high temperatures can shorten the setting time of CPC pastes. ${ }^{7)}$ To date, the effects of short setting times achieved by including heating process on the mechanical and chemical properties of the resulting CPCs are unclear.

In the present work, CPC pastes were heated at different temperatures during the initial setting process. The influences of temperature on the compressive strength and operating hydration reactions within the $\mathrm{CPC}$ setting bodies were examined.

\section{Experimental procedure}

Dicalcium phosphate anhydrous (DCPA; $\mathrm{CaHPO}_{4}$, Taihei Chemical Industrial, Nara, Japan; mean particle size of $8.0 \mu \mathrm{m}$ ) was milled with distilled water for $24 \mathrm{~h}$ using an alumina ball

Corresponding author: T. Sawamura; E-mail: t-sawamura@mg. ngkntk.co.jp mill, and dried at $120^{\circ} \mathrm{C}$ for $20 \mathrm{~h}$ following our previous work. ${ }^{8)}$ The resulting DCPA sample featured a mean particle size of $0.6 \mu \mathrm{m}$. Tetracalcium phosphate $\left[\mathrm{TeCP} ; \mathrm{Ca}_{4}\left(\mathrm{PO}_{4}\right)_{2} \mathrm{O}\right]$ was prepared as follows: the mixture consisting of dicalcium phosphate dihydrous $\left(\mathrm{CaHPO}_{4} \cdot 2 \mathrm{H}_{2} \mathrm{O}\right.$; Kanto Kagaku, Tokyo, Japan) and calcium carbonate $\left(\mathrm{CaCO}_{3}\right.$; Kanto Kagaku, Tokyo, Japan) at a weight ratio of $1.75: 1$ was fired at $1550^{\circ} \mathrm{C}$ for $10 \mathrm{~h}$ and then quenched at room temperature. The resulting matter was crushed to prepare powders with an average particle size of $200 \mu \mathrm{m}$. The raw CPC powders were prepared by mechanically mixing $67.5 \mathrm{~g}$ $\mathrm{TeCP}$ and $32.5 \mathrm{~g}$ DCPA using an automatic mortar. A $48.7 \mathrm{wt} \%$ dextran sulfate sodium aqueous solution (Meito Sangyo, Aichi, Japan) was used as mixing liquid. The raw CPC powders were mixed with the mixing liquid at a liquid-to-powder mass $(\mathrm{g})$ ratio of $0.26: 1$ for $1 \mathrm{~min}$ at room temperature to prepare the CPC paste. The resulting CPC paste was filled in a stainless steel ring $(10 \mathrm{~mm}$ in inner diameter, $5 \mathrm{~mm}$ in height) and flattened on its top surface to measure the setting time. A Vickers needle $(300 \mathrm{~g}$ in weight, $1 \mathrm{~mm}^{2}$ in cross-sectional area) was set on the top surface of the filled CPC paste at $37,60,80$, or $100^{\circ} \mathrm{C}$. The setting time was determined as the point at which no indent was formed by the needle $(\mathrm{n}=5)$. The CPC paste was molded into disks of $6 \mathrm{~mm}$ in diameter and $12 \mathrm{~mm}$ in height, and heated at 37, 60, 80, or $100^{\circ} \mathrm{C}$ for the initial setting process. Some reports have been shown the evaluation on the compressive strength of CPC after soaking in simulated body fluid (SBF). ${ }^{9), 10)}$ In the present work, after $5 \mathrm{~min}$ of heating, the $\mathrm{CPC}$ setting bodies were soaked in $\mathrm{SBF}$ at $37^{\circ} \mathrm{C}$ for $24 \mathrm{~h}$.

The compressive strength of the CPC setting bodies before and after the SBF soaking was evaluated on an Universal Testing Machine (Autograph AGS-5kND; Shimadzu, Kyoto, Japan). Following compressive strength measurements, the samples were immediately soaked in acetone for $1 \mathrm{~h}$ and dried under vacuum for $24 \mathrm{~h}$. The crystalline phase of the dry ground fine powders was identified by X-ray diffraction (XRD; RU-200; Rigaku, 
Tokyo, Japan). The relative intensity of HA phase was calculated from XRD patterns using the following equation:

Relative intensity of HA $(\%)=\left[I_{H A} /\left(I_{D C P A}+I_{T e C P}+I_{H A}\right)\right]$

$$
\times 100
$$

$I_{D C P A}:$ Intensity of DCPA (020), $2 \theta=26.4^{\circ}$

$I_{T e C P}$ : Intensity of TeCP (200), $2 \theta=25.3^{\circ}$

$I_{H A}:$ Intensity of HA (002), $2 \theta=25.9^{\circ}$

The microstructure of the raw CPC powders and fracture surfaces of the dry samples were observed by scanning electron microscopy (SEM; S-2500; Hitachi, Tokyo, Japan).

\section{Results and discussion}

In the present work, the relationship between the compressive strength and setting reaction at initial setting temperature was investigated for clinical application.

Table 1 shows the setting time of the CPC paste at each initial setting temperature. The time shortened with increasing the initial setting temperature. The setting time of the paste heated at 80 or $100^{\circ} \mathrm{C}$ was drastically short, that is, within $2 \mathrm{~min}$.

Figure 1 shows the compressive strength of the CPC setting bodies. The samples prepared at higher temperatures possessed higher strength following initial setting for $5 \mathrm{~min}$ when compared with those prepared at lower temperatures. In contrast, samples prepared at higher temperatures followed by SBF soaking featured lower strength properties relative to those prepared at lower temperatures followed by SBF soaking. No collapse of CPC occurred after soaking in SBF. The CPC setting bodies heated at $37^{\circ} \mathrm{C}$ showed the highest compressive strength, $\sim 50 \mathrm{MPa}$, following SBF soaking; prior to soaking, they featured a compressive strength of $<2 \mathrm{MPa}$. Conversely, the CPC setting bodies heated at $100^{\circ} \mathrm{C}$ displayed compressive strengths of $\sim 14$ and $\sim 18 \mathrm{MPa}$ before and after SBF soaking, respectively.

Figure 2 shows the XRD patterns of the CPC setting bodies. The setting bodies heated at $37^{\circ} \mathrm{C}$ displayed almost no changes in the crystalline phases following initial setting. Contrarily,

Table 1. Setting time of $\mathrm{CPC}$ pastes at each initial setting temperature

\begin{tabular}{ccccc}
\hline Initial setting temperature & $37^{\circ} \mathrm{C}$ & $60^{\circ} \mathrm{C}$ & $80^{\circ} \mathrm{C}$ & $100^{\circ} \mathrm{C}$ \\
\hline Setting time (min) & $9.2 \pm 1.1$ & $4.2 \pm 0.4$ & $2.4 \pm 0.5$ & $2.0 \pm 0.0$ \\
\hline
\end{tabular}

Data represent average values with associated standard deviations obtained from five measurements.

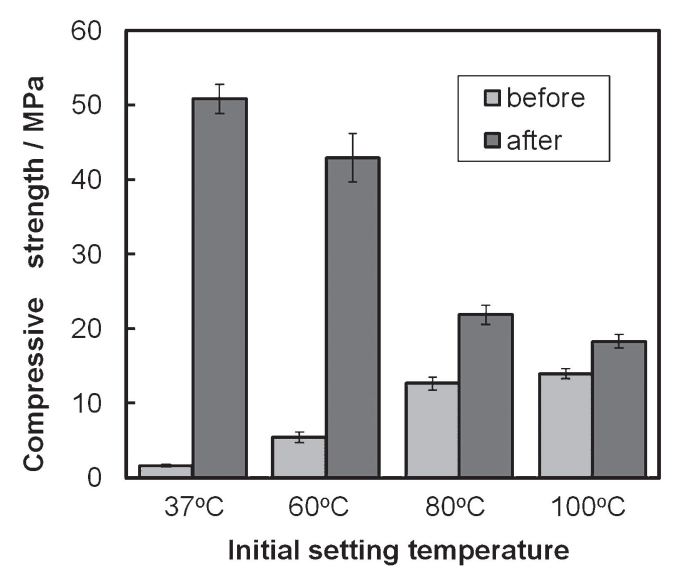

Fig. 1. Compressive strengths of the CPC setting bodies obtained at different initial setting temperatures before and after SBF soaking at $37^{\circ} \mathrm{C}$ for $24 \mathrm{~h}$. Data represent average values with associated standard deviations obtained from five measurements. hydroxyapatite (HA) peaks appeared following SBF soaking accompanied with a decrease in the intensity of the TeCP and DCPA peaks. In contrast, the setting bodies heated at $100^{\circ} \mathrm{C}$ displayed HA peaks and the intensity of the TeCP and DCPA peaks decreased following initial setting. Small changes in the intensity of $\mathrm{HA}, \mathrm{TeCP}$, and DCPA peaks were observed following $\mathrm{SBF}$ soaking. The sample heated at $37^{\circ} \mathrm{C}$ followed by SBF soaking showed a higher peak intensity of the HA phase and lower peak intensities of the TeCP and DCPA phases, when compared with counterpart sample heated at $100^{\circ} \mathrm{C}$.

Figure 3 shows SEM images of the CPC powders and the fracture surfaces of the CPC setting bodies. DCPA particles $(\sim 0.5 \mu \mathrm{m}$ in size) were clearly observed in the CPC powders. For the setting bodies heated at $37^{\circ} \mathrm{C}$, although DCPA particles were observed after $5 \mathrm{~min}$, following SBF soaking, they almost

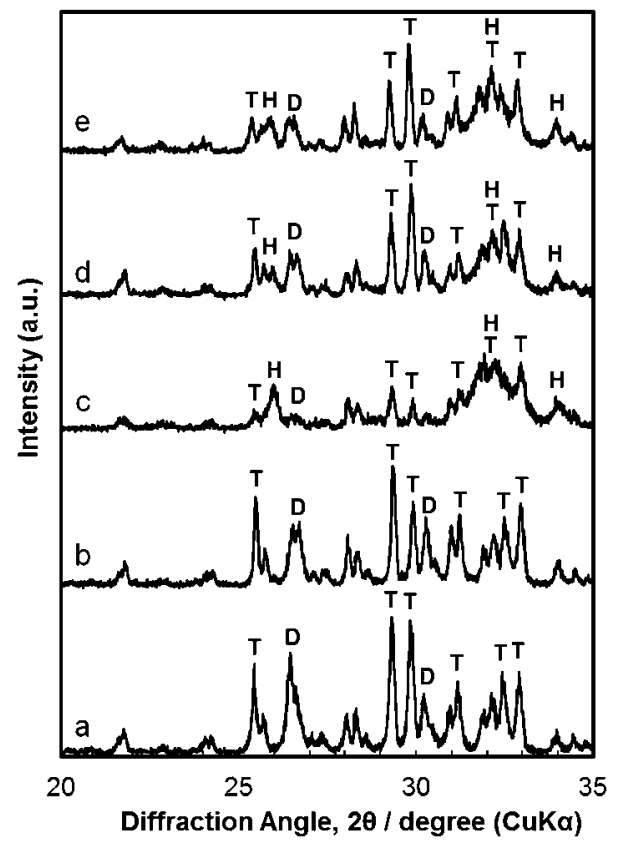

Fig. 2. X-ray diffraction patterns of (a) CPC powders, and CPC bodies set at $37^{\circ} \mathrm{C}$ for $5 \mathrm{~min}(\mathrm{~b})$ before and (c) after SBF soaking and $\mathrm{CPC}$ bodies set at $100^{\circ} \mathrm{C}$ for $5 \mathrm{~min}(\mathrm{~d})$ before and (e) after SBF soaking. (H) HA; (T) TeCP; (D) DCPA.
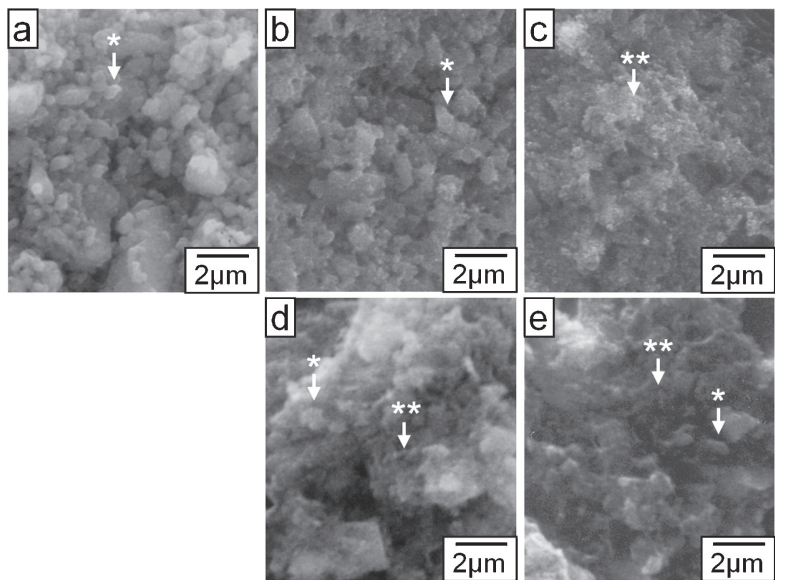

Fig. 3. Scanning electron microscopy images of (a) CPC powders, and fracture surfaces of $\mathrm{CPC}$ bodies set at $37^{\circ} \mathrm{C}$ for $5 \mathrm{~min}$ (b) before and (c) after SBF soaking and CPC bodies set at $100^{\circ} \mathrm{C}$ for $5 \mathrm{~min}$ (d) before and (e) after SBF soaking. (*) DCPA; $\left(^{* *}\right)$ HA. 


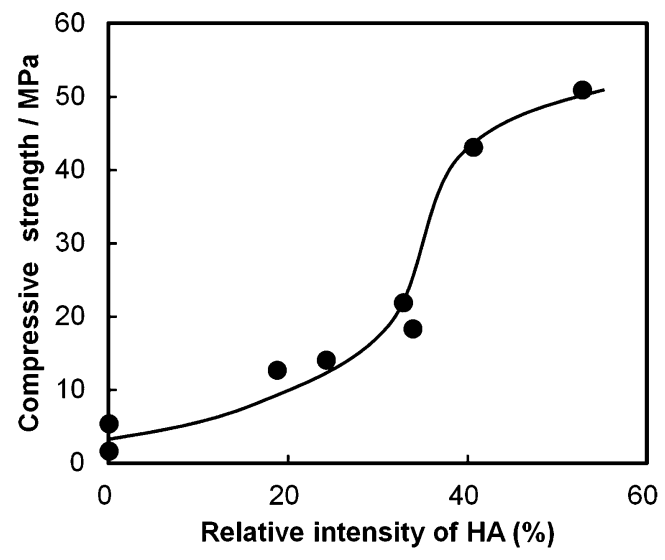

Fig. 4. Compressive strengths of the CPC setting bodies as a function of the relative intensity of HA.

disappeared and numerous submicrometer-sized particles that are believed to be HA (based on XRD analysis) were observed [Fig. 2(c)], as consistent with previous report. ${ }^{11)}$ In contrast, for the CPC setting bodies heated at $100^{\circ} \mathrm{C}$, DCPA particles and HA were observed in the sample after $5 \mathrm{~min}$. Almost no changes were observed following SBF soaking.

Figure 4 shows the compressive strength of CPC setting bodies as a function of the relative intensity of HA in XRD patterns. The compressive strength of CPC increased with increasing the relative intensity of HA. The initial setting temperature employed significantly influenced the compressive strength and HA formation. This is believed to originate from the difference in the setting behavior and operating hydration reactions in CPC. The initial hydration reaction rate in CPC increased with increasing initial setting temperatures that contributed to the increase in the compressive strength. In contrast, the CPC sample following SBF soaking for $24 \mathrm{~h}$ displayed a reduced compressive strength and delayed HA formation with increasing initial setting temperatures. The difference in HA formation was observed in the XRD and SEM analyses. It has been reported that the diametral tensile strength of $\mathrm{CPC}$, which was prepared from a neutral sodium hydrogen phosphate $\left(\mathrm{Na}_{x} \mathrm{H}_{3-x} \mathrm{PO}_{4}\right)$ solution as mixing liquid, is dependent on the conversion amounts to HA. ${ }^{12)}$ In the present work, the compressive strength increased with increasing amounts of HA and decreasing amounts of TeCP and DCPA.

TeCP and DCPA gradually dissolved and supplied $\mathrm{Ca}^{2+}$ and $\mathrm{PO}_{4}{ }^{3-}$ ions to the mixing liquid, thus increasing the supersaturation level of HA. Finally, HA formed in the CPC body. Therefore, the hydration reaction rate is expected to increase with increasing initial setting temperatures, consequently enhancing HA formation. This contributed to an increase in the compressive strength following initial setting. Contrarily, shorter setting times and higher compressive strengths were achieved upon addition of HA prepared at $37^{\circ} \mathrm{C}$ in comparison with that prepared at $100^{\circ} \mathrm{C}$ : the hydration of CPC would be influenced by the difference in HA crystallinity between the two thermally prepared samples. ${ }^{13)}$ It was reported that the crystallinity of HA obtained by a wet preparation method increased with increasing preparation temperatures. ${ }^{14)}$ In the present work, it was difficult to evaluate the crystallinity of HA precipitated in CPC setting bodies by XRD analysis because of their low crystallinity. However, we believe that the crystallinity of HA in CPC varies with initial setting temperatures. The hydration reaction in $\mathrm{SBF}$ was delayed with increasing initial setting temperatures, especially at $100^{\circ} \mathrm{C}$. It is believed that highly crystalline HA formed in the initial setting bodies heated at high temperatures. This may be due to the change in solubility of DCPA and TeCP following heating.

Control of the hydration reaction by varying the initial setting temperature is expected to prevent inflammation owing to CPC collapse after implantation.

\section{Conclusion}

The compressive strength of CPC following initial setting increased with increasing initial setting temperatures, whereas that of $\mathrm{CPC}$ following SBF soaking at $37^{\circ} \mathrm{C}$ for $24 \mathrm{~h}$ was not drastically enhanced with increasing initial setting temperatureshydration reactions were delayed. This was likely because of the difference in the crystallinity of the formed HA and the change in the solubility of DCPA and TeCP during initial setting.

\section{References}

1) M. Bohner, M. Gbureck and J. E. Barralet, Biomater, 26, 6423-6429 (2005).

2) L. David, L. Argenta and D. Fisher, J. Craniofacial Surg., 16, 129-133 (2005).

3) H. Saijo, U. Chung, K. Igawa, Y. Mori, D. Chikazu, M. Iino and T. Takato, J. Artif. Organs, 11, 171-176 (2008).

4) M. A. Tañag, T. Madura, K. Yano and K. Hosokawa, Plast. Reconstr. Surg., 117, 1186-1193 (2006).

5) Y. Ueyama, K. Ishikawa, T. Mano, T. Koyama, H. Nagatsuka, T. Matsumura and K. Suzuki, J. Biomed. Mater. Res., 55A, 652-660 (2001).

6) F. C. M. Driessens, M. G. Boltong, E. A. P. De Maeyer and R. M. H. Verbeeck, J. Mater. Sci.: Mater. Med., 11, 453-457 (2000).

7) J. E. Barralet, M. Tremayne, K. J. Lilley and U. Gbureck, Chem. Mater., 17, 1313-1319 (2005).

8) T. Sawamura, Y. Mizutani, M. Okuyama and T. Kasuga, J. Mater. Sci.: Mater. Med., 25, 1631-1636 (2014).

9) T. Kokubo and H. Takadama, Biomater, 27, 2907-2915 (2006).

10) K. Takahashi, Y. Fujishiro, S. Yin and T. Sato, Ceram. Int., 30, 199-203 (2004).

11) M. P. Ginebra, E. Fernández, E. A. P. De Maeyer, R. M. H. Verbeeck, M. G. Boltong, J. Ginebra, F. C. M. Dressens and J. A. Planell, J. Dent. Res., 76, 905-912 (1997).

12) Y. Miyamoto, K. Ishikawa, H. Fukao, M. Sawada, M. Nagayama, M. Kon and K. Asaoka, Biomater., 16, 855-860 (1995).

13) Y. Takezawa, Y. Doi, T. Shibata, N. Wakamatsu, H. Kamemizu, T. Goto, M. Iijima, Y. Moriwaki, K. Uno, F. Kubo and Y. Haeuchi, Sikazairyou Kikai, 6, 426-431 (1987) [in Japanese].

14) Y. X. Pang and X. Bao, J. Eur. Ceram. Soc., 23, 1697-1704 (2003). 